\title{
Difficulties Encountered by Sudanese Students in Translating Idiomatic Expressions from English into Arabic
}

\author{
${ }^{1}$ Mousab Alata Elseddig Adiel, ${ }^{2}$ Dr. Mahmoud Ali Ahmed \\ ${ }^{1}$ Lecturer at University of Dammam \\ ${ }^{2}$ Associate Professor, College of Languages, University of Sudan for Science and Technology
}

\begin{abstract}
This study sets out to investigate the types of hurdles Sudanese EFL learners are likely to run into upon translating English idiomatic expressions. The study also seeks to provide remedies as part of the investigation for these mistakes after giving a thorough account of their occurrence.

As many as 40 undergraduate students at Sudan University of Science and Technology were given a pre-test comprising 20 idiomatic expressions to translate into Arabic. They were then divided into two groups namely control and experiment group. After two months of active work with the experiment group a post-test was administered to the two groups. The experiment group scored significantly high marks due to the excessive training they received. Therefore, students can be trained to translate idiomatic expressions.
\end{abstract}

\section{The Discipline of Translation Studies}

Quite a number of names have been suggested to refer to the discipline that takes translation as its point of departure, such as science of translation (e.g. Nida 1964 and 1969) and translatology (or tradutologie in French, Goffin 1971). In the long run, those names were steadily discarded or forsaken and the term translation studies became the standard name to refer to the discipline. Mona Baker notes that the term 'translation studies' was associated, at one time, with literary translation; however, it "is now understood to refer to the academic discipline concerned with the study of translation at large, including literary and non-literary translation, various forms of oral interpreting, as well as dubbing and subtitling" (Baker 1998b: 277).

James Holmes was considered by many to be the first translation scholar to design a clear cut path to the academic field of Translation Studies. His classic paper 'The Name and Nature of Translation Studies' has become a solid reference for those who seek to give the theory of translation a proper academic status.

Early studies in translation in the 1950s were classified under the discipline of linguistics (Baker 1998). Because scholars began to notice that "only a limited number of issues in linguistics are relevant to translation, and that linguistic models can hardly ever be adopted wholesale" (SnellHornby 1988) ideas and concepts from neighboring disciplines started to creep into the field these like psychology communication theory, literary theory and so forth began to enter the realm since 1970s, which contributed quite remarkably to the theory of translation. So the interdisciplinary nature of the science began to emerge and take shape.

\section{Translation Strategy}

Krings (1986, p.18) defines translation strategy as "translator's potentially conscious plans for solving concrete translation problems in the framework of a concrete translation task," and Seguinot (1989) believes that there are at least three global strategies employed by the translators:

- translating without interruption for as long as possible;

- correcting surface errors immediately;

- Leaving the monitoring for qualitative or stylistic errors in the text to the revision stage.

Loescher (1991, p.8) defines translation strategy as "a potentially conscious procedure for solving a problem faced in translating a text, or any segment of it." As it is stated in this definition, the notion of consciousness is significant in distinguishing strategies which are used by the learners or translators. In this regard, Cohen $(1998$, p.4) asserts that "the element of consciousness is what distinguishes 
strategies from these processes that are not strategic." Jaaskelainen $(1999$, p.71) considers strategy as, "a series of competencies, a set of steps or processes that favor the acquisition, storage, and/or utilization of information." He maintains that strategies are "heuristic and flexible in nature, and their adoption implies a decision influenced by amendments in the translator's objectives."

Stated firmly in an article entitled "Interview and translation strategies: coping with multilingual settings and data" (2009) B. Filep focuses on the challenges and questions interview and translation strategies. He believes that, the translator should first know that what are should be the good strategies for the translators and what a translator should do in order to find equivalences in translating unfamiliar lexicons and expressions. He focuses on the deconstruction of the meaning of geographical names and politically loaded expressions in order to show these sensitivities of language, the difficulties of research in multilingual settings.

According to Straksiene (2009), one of the problems a translator faces in translating idioms is the lack of equivalence on the idiom level. All languages have idioms. But it is not easy to find an equivalent in the TL that corresponds to the idiom in the ST in both form and meaning. Idioms may contain a culturebound item and this poses a problem for the translator.

\section{NATURE OF IDIOMATIC EXPRESSIONS}

It goes without saying that the basic tenet of translation is communication. Quite often we come across expressions of the type "Translation is a means of communication". So, people belonging to two different ethnicities can only communicate through translation. They can exchange knowledge, benefit from research written in foreign languages....etc. The development of science and technology in this modern age becomes an integral part of translation activity because most of original information is written in English such as, science, medicine, opinion and reality. Therefore, if there is no translation, people do not understand the content. For that reason, translation is very important in order to convey to the readers or trainees the real meaning and same information written in the source language.

The process of translation becomes even tougher when a translator embarks on translating a stretch of language which includes cultural, scientific, literary, or idiomatic expressions. The basic challenge is passing on the real meaning of the source language into the target language. A number of factors are responsible for such an occurrence, namely culture, environment, and finding the most equivalent words in the target language.

Nida (1964) affirmed that "in order to achieve an equivalent response, the translation should make sense; convey the spirit and the manner of the original; have natural and easy form of expressions" (p.164). He suggested two main types of equivalence:

1. Formal equivalence: in which the translator focuses his attention on the similarity of form between the source language and the target language texts, as well as on the content in order to enable the target language reader to grasp and understand as much as possible of the original text.

2. Dynamic equivalence: In which the translator has to reproduce an equivalent effect on the receiver as that experienced by the source language receiver.

Nida (1964, p.13) also confirmed that "the role of a translator is to facilitate the transfer of the message, meaning, and cultural elements from one language into another and create an equivalent response to the receivers".

Language, as a system of communication has literal and figurative meanings. The literal meaning is the direct meaning of words or sentences to objects which do not imply implicit meaning (what the individual word implies is the actual meaning), while the figurative sense is used for giving an imaginative description or a special effect which means it implies a hidden meaning which cannot be predicted from the meaning of individual words. Such a meaning includes notions like metaphors, similes and proverbs.

In the present article, the researchers are particularly interested in considering idiomatic expressions and the challenges they pose when rendered from English into Arabic.

As far as language use is concerned, Idiomatic expressions are an ordinary part of that use. I $t$ is taken for granted that people never pause to think over the use of these expressions as they are normally used in the course of their daily life. An idiomatic expression is a colloquial metaphor that requires 
fundamental knowledge and experience in both the target and source languages, and the translator must have cultural background of both the source and target texts. According to Langlotz (2006, p. 2) "idioms have been described as conventional multi-word units that are semantically opaque and structurally fixed". Healey (1968, p.71) defined an idiom as "any group of words whose meaning cannot be deduced from the meaning of the individual words". This contradicts the principle of compositionality, which states that the meaning of a complex expression can be determined by the meaning of its constituents. The main existing problem in this regard is that translating the meaning of idiom's constituents instead of translating it as a single unit. For example, the sentence "A chip off the old block" will be translated into Arabic as " شريحة من زند الخشب " instead of من شابه أباه فما ظلم . In the first instance the idiom is translated literally, whereas in the second it is rendered literary. Hence, the second rendering conveys the meaning readily and correctly.

An idiom is composed of two or more words and these words if taken separately they add nothing to the overall meaning intended to be conveyed. Taken together, the overall meaning of these words expresses a completely different idea. The reasons for this semantic abnormality is due to the fact that an idiom is not built word by word, but it is a non-compositional phrase which is learned, stored and recycled as a single item.

As their meanings can hardly be arrived at from translating the individual words comprising them, idioms are thus set distinct from all other types of expressions. Idiomatic expressions are said to be frozen or lacking flexibility. They are different from collocations and all patterns of language which allow several movements and changes in form and meaning of the word or words. Idioms do not have such elasticity.

In her "In Other Words" Baker (1992) stated that, idioms are frozen patterns of language. An idiom such as the long and the short of it ('the basic facts of the situation') allow no changing in the form of idiom under normal circumstances unless someone is consciously making a joke or attempting a play on words. Idioms are fully conceived of as having the following restrictions:

- Change the order of the words within idioms; (the short and the long of it)

- Delete a word from the phrase containing this idiom;( spill beans)

- Add a word to the idiom; (the very long)

- Replace a word by another; (the tall and the short)

- Change its grammatical structure. (the music was faced)

\section{INTERPRETING IDIOMS}

One of the awkward pitfalls translators are often unaware of is that when they translate idiomatic expressions. There are idioms which are not readily identifiable. There is a full range of idioms in which some are easily recognizable. This category includes expressions which violate truth conditions, such as It is raining cats and dogs, and food for thought.

Expressions which look badly-formed as they do not lend up themselves to the known rules of grammar are idiomatic, such as jump down ones throat, by and large, the world and his friend. In this category falls the expressions which start with like (simile-like structures) and they should not be interpreted literally, like a boat out of hell.

By and large, the more difficult an expression is to understand and less sense it makes in a given context, the more likely a translator will recognize it as an idiom.

\section{STRATEgIES FOR TRANSLATING IDIOMS}

There have been many scholars writing about various strategies to be used for rendering a text from L1 into L2 during the history of translation. Apart from translating isolated words, "the most typical exampleof translating on the level of the combination of words is the translation of idiomatic or phraselogical units" (Catford, 1965, p. 44). He also argues that the meaning of such units is not identical with the total meaning of their constituents and it is impossible to translate such units word forword in most cases. The idiom or phrase is considered as "the unit of translation: (ibid).

Catford (1965, p.54) further states that idioms and phraseological units should not be considered as “ the only possible translation units on the level of combination of words ". In many times, such a unit 
can be "a free combination of words whose source language meaning is built up out of the meaning of its separate components."

Translating idiomatic expressions poses a factual challenge to undergraduate students, especially in the case of Arabic which is a Semitic language quite distant from English Language an Indo-European Language. In figurative language area especially the arena of idioms the situation becomes even tougher. Cultural distance is responsible for any wrong rendering.

Hansen, Malmkjaer, and Gile (2004, p. 64) mention that " the meaning of an idiomatic expression cannot be deducted by examining the meaning of the constituent lexemes".

Baker (1992) argues that a person's competence for using idioms and fixed expressions of a foreign language is not comparable with that of a native speaker. She suggests that most of the translators working into a foreign language cannot hope to achieve the same sensitivity of the native speakers of a language in judging when and how an idiom can be manipulated.

Newmark (1988) believes that for most texts, the translator has to make sure that 1) his/her translation makes sense and 2) it reads naturally, written in ordinary language, using the common grammar, idioms and vocabulary that meet the situation. He also states that the natural use of language comprises different idioms, styles or registers which are determined by a) the setting of the text and b) the author, topic and readership (Newmark, 1988). He distinguishes between the translation of idioms and idiomatic translation and says that idiomatic translation "reproduces the messageof the original but tends to distort nuances of meaning by preferringcolloquialisms and idioms where these do not exist in the original" (Newmark, 1988, p. 47).

Larson (1984, p.49) points out: translators who want to make a good idiomatic translation often find figures of speech especially challenging. A literal translation of as blind as a bat might sound really strange in a language where the comparison between a blind person and $a$ bat has never been used as a figure of speech. In Aguaruna it would be more natural to say blind as a fox. There is a legend in which the sun borrowed the fox's eyes and then returned to heaven taking the fox's good eyes with him and leaving the fox with the sun's inferior eyes.

\section{LITERATURE REVIEW}

To the best of the researcher's knowledge, this study is not the only study that has been conducted in this area. There are some studies that have dealt with the translation of idiomatic expressions in the Arab world. This study may fill a gap in the literature. There are studies that have handled other types of figurative language, such as metaphor and simile. This study will be of great use to both students and tutors. It will furnish students with the required information to handle texts dealing with idiomatic expressions.

\section{REFERENCES}

Azabdaftari, B. (1997). Psychological Analysis of Translation Process.

Motarjem JournalMashhad, Iran. 21 \& 22: 7-12 (Translation).

Baker, M. (1992).In Other Words, a coursebook on Translation. London: Routledge.

Bassnett, S. (2002).Translation Studies(3rded.). London and New York: Routledge.

Catford, J. C. (1965). A Linguistic Theory of Translation. London: Oxford University Press.

Che Sue, J. (2005). A study of Translation Strategies in Guillaume OyonoMbia' plays.South Africa: University of South Africa.

Cohen, A.D. (1984). On taking tests: what the students report. Language testing,11(1).70-81.

Davies, M. G. (2004). Multiple voices in the translation classroom: Activities, tasks and projects. Amesterdam and Philadelphia: John Benjamins.

Eftekhari, N. (2008). A Brief Overview on Idiomatic Translation. Retrieved from http://www. translationdirectory.com/articles/article1739.php

Gottlieb, H. (1997). Quality Revisited: The Rendering of English Idioms in Danish Television Subtitles vs. Printed Translation. In A. Trosborg (ed.), Text Typology and Translation(pp. 309 338).Amesterdam: John Benjamins B.V.

Helleklev, C. (2006). Metaphors and terminology in social science: A Translation and an analysis. Sweden: Vaxjo University. 
Jaaskelainen, R., (1999). Tapping the process: an explorative study of cognitive and effective factors involved in translating. Joensuu: University of Joensuu Publications in Humanities.

Jensen, K. E. (2008), metaphors and idioms in translation + feedback on assignment\# 4. Retrieved from www.hum.aau.dk/ kim/TRO08/TROLN7.

Krings, H.P. (1986). Translation problems and translation strategies of advanced German learners of French.In J. House, \& S. Blum-Kulka (Eds.), Interlingual and intercultural communication (pp. 263-75). Tubingen: Gunter Narr.

Larson, M. L. (1984). Meaning-based Translation: Lanham: University Press of America.

Loescher, W. (1991). Translation performance, translation process and translation strategies. Tuebingen: GutenNarr.

\section{AUTHOR'S BIOGRAPHY}

${ }^{1}$ Mousab Alata Elseddig,

\section{Scientific Qualifications}

- BA, Honors degree, Division one in English \& Arabic languages from Institute of Translation KRT/2010.

- Master in Translation (Arabic- English-Arabic) from International University of Africa KRT/2014.

— Ph.D. candidate (college of languages/Sudan University of Science \& Technology)

\section{Work Experience}

* A translator for Ministry of Finance (In North -Darfur / Sudan).

* English language lecturer at Omdurman Islamic University.

${ }^{2}$ Dr. Mahmoud Ali Ahmed

Associate Professor, College of Languages, University of Sudan for Science and Technology 